\title{
Solar Panel Cleaning System Using Voltage Comparison
}

\author{
R.Sivaprasad ${ }^{1}$, Pradeep Krishna $\mathrm{K}^{2}$,Keerthivasan $\mathrm{A}^{3}$, Akash S $\mathrm{P}^{4}$, Navin Sarveswaran S A \\ \{ sivaprasad.eee@sairam.edu.in'1, e7ee062@sairamtap.edu.in², e7ee021@ sairamtap.edu.in ${ }^{3}$, \\ e7ee088@sairamtap.edu.in ${ }^{4}$, e7ee089@ sairamtap.edu.in $\left.{ }^{5}\right\}$ \\ Associate Professor, \\ Department of Electrical and Electronics Engineering \\ Sri Sairam Engineering College \\ Chennai, India ${ }^{1}$, Undergraduate Student \\ Department ofElectrical and Electronics Engineering, \\ Sri Sairam Engineering College \\ Chennai, India ${ }^{2}$
}

\begin{abstract}
The pollution not only causes harm to the surroundings but also deposits on the solar panel. Besides pollution dust and debris carried by the wind also deposit on solar panel's surface. Soiling reduces the amount of sunlight incident on the surface of the panel thereby reduces the output produced. To avoid that manual cleaning is done at present. But the process is not continuous and not done periodically so there is a loss of output voltage and current produced from the panel. Thus an automatic solar panel cleaning system is designed, which detects dust by comparing the reference voltage and present voltage measured and cleans by itself until the dust removed.
\end{abstract}

Keywords: Automatic, Solar Panel, Cleaning System, Voltage Comparison.

\section{Introduction}

Our proposal's main intent is to clean solar panels automatically to increase the efficiency of panels. It is proven that the efficiency of solar panel may be reduced to $10 \%$ from soiling alone. Some articles says about reduction in output by soiling reduces the revenue of an individual using solar panel. It would cost higher for commercial works hence, we used small sized panel of 20V.There were several considerations taken when designing this system. In case of residential use, solar panels are usually placed on the roof or terrace to receive the maximum amount of sunlight. But cleaning the panels by climbing up is dangerous. The proposed system is designed should be automatic to avoid men labour for cleaning it. A large research is made on it by comparing our idea to the existing systems. The Ecoppia E4 and Heliorex sprinkler systems are mostly employed to clean the panels. The Ecoppia E4 system needs manual supervision and it is too costly to install which is not affordable for middle class. The other hand Heliotex wastes large amount of water by sprinkler. The drones and robots are the other pick for cleaning the system. The proposed system is an automated system cleans the solar panel whenever dust formed on the panel. Water spitter is used to control the temperature. The voltage drops when the dust is formed, this is the idea used in this system here we refer that as set point. This is a fully automated system which works as per the set point. When the set point comes, the system automatically turns on the water spitting and then 
automatically the movement of the shaft is started. By this way, our solar panel cleaning system by Arduino is done.

\section{Objectives}

- The solar panel must be cleaned effectively.

- The manual work should be avoided.

- The problems by soiling must be avoided.

- The overall panel efficiency should be improved.

- The cleaning system should be more affordable.

\section{Literature Review}

- Masuda S. et. al, This paper explains that, the solar panel is coated with a semiconducting film and theelectrodes are attached to a single phase AC signal or to a multiphase AC signal that produces a travelling electromagnetic wave. This is a transparent technique used for solving the problem.

- Williams R B. et. al, This paper says that, an Electro Dynamical Screen based system requires a HV external power source for its operation, but the EDS can be made selfsustainable with the power output from the PV cell itself. The cleaning is made such a way a transparent EDS with a PV array as its power source to make it more effective.

\section{Hardware Required}

- Solar panel(20 V)

- Photo Resistor(5V)

- Arduino UNO

- DC Motor 12V

- Water pump motor

- $12 \mathrm{~V}$ Battery

- Two channel relay

- Worm drive

- Silicone pipes

- 1 inch square tube(mild steel)

- $16 \mathrm{~mm}$ mild steel rod

- Table Wiper

- Voltage divider(using Resistors)

\section{Software Required}

- Arduino IDE

- Silvaco

\section{Designing Of Model}




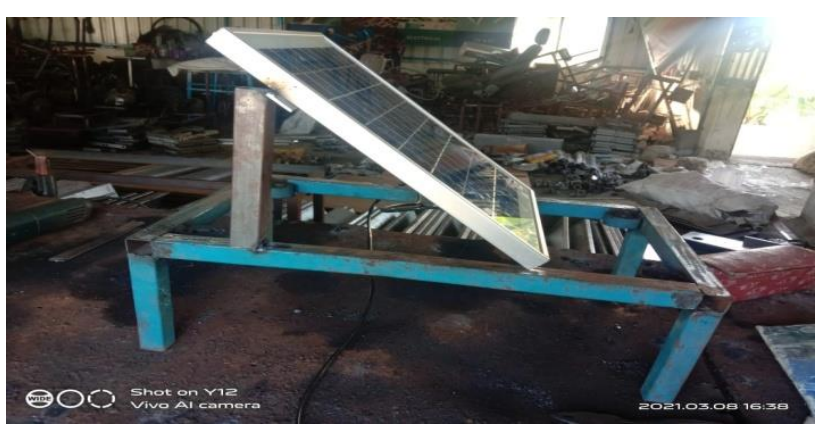

Fig 0.1 Setup for the Solar Panel

The base for holding the solar panel is made of 1 inch square tube inclined at $45^{\circ}$ as shown in Fig 0.1. Mild steel is used to withstand the weight of solar panel and the above apparatus.

\section{Methodology}

The solar panel cleaning system consists of following units.

1. Solar Panel Unit

2. External Monitoring Unit (Photo Resistor Circuit)

3. Processing Unit (For Checking Condition)

4. Cleaning unit

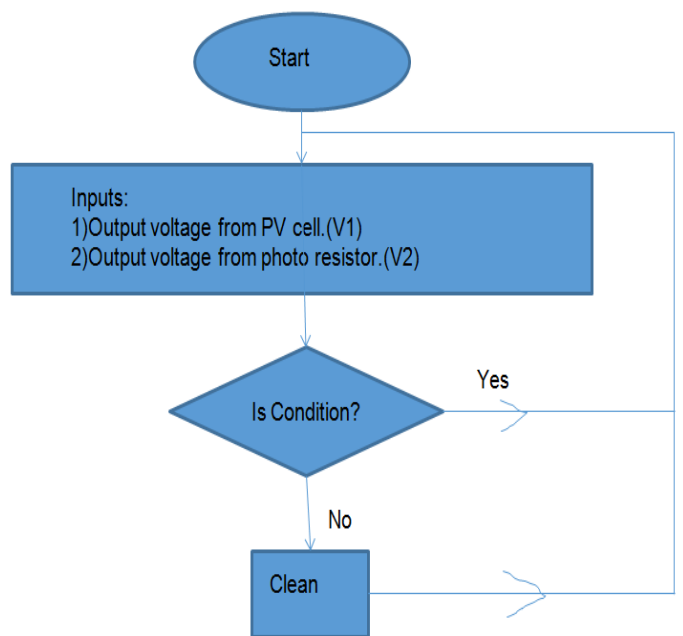

Fig 1.1 Flow Chart for Proposed System

The above Fig 1.1 shows the flowchart of our model. The output of the Solar Panel unit and the output of the EMU (External Monitoring Unit) are compared based on a condition. We referred the condition as setpoint which will be discussed later. If the condition is satisfied there is no need of activating the cleaning system but in another case the cleaning system cleans the entire system. 


\subsection{Solar Panel Unit}

The Solar Panel unit varies from different usages. For our model we have used 20V, 10W Solar Panel.

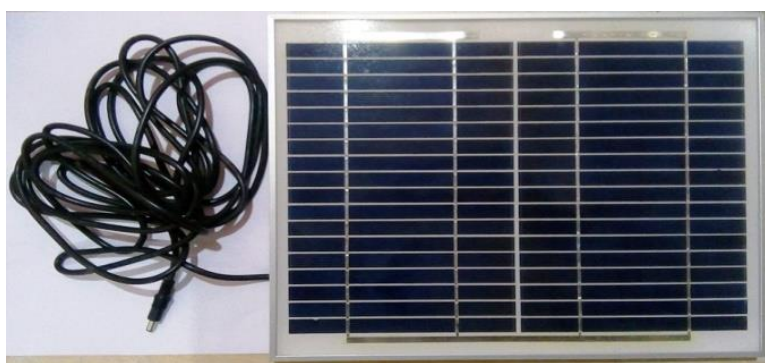

Fig 1.1.1 Solar Panel used in our System

The voltage output of the solar panel with respect to light intensity is not linear. The various outputs of the solar panel are monitored by using Silvaco software.

$$
\text { ATLAS }
$$

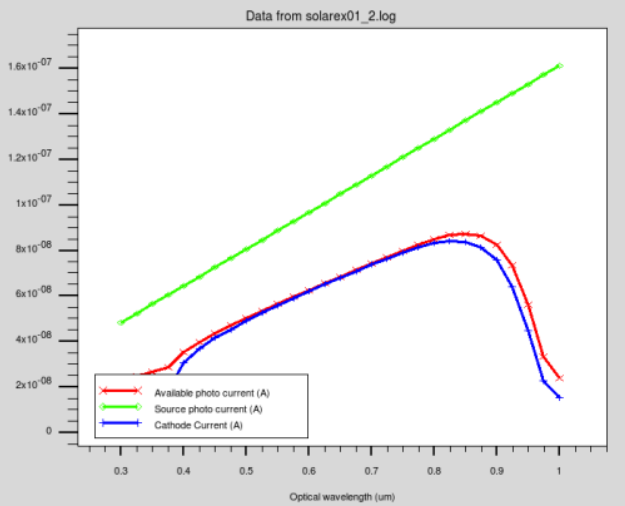

Fig 1.2 Opt. Wavelength vs Current

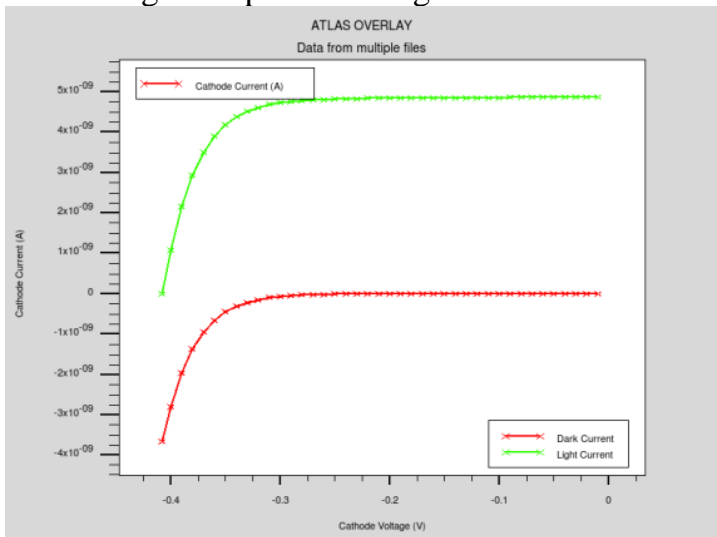

Fig 1.3 Cathode Voltage vs Cathode Current 


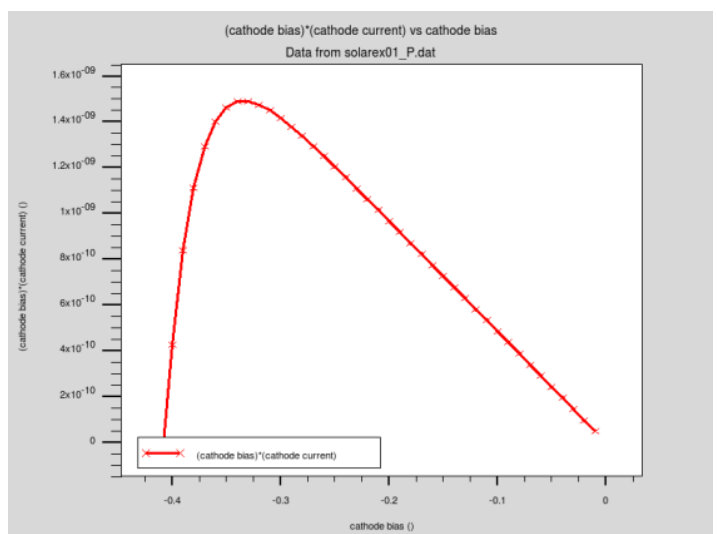

Fig 1.4 Cathode Bias vs Cathode Bias*Cathode Current

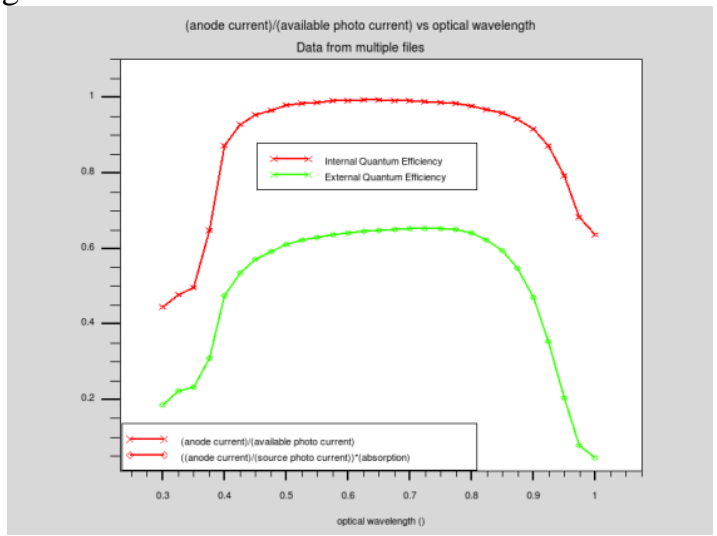

Fig 1.5 Opt. Wavelength vs Current Efficiency

From the two graphs Fig. 1.2 and Fig. 1.3 it is noted that the voltage increases with respect to increase in light intensity up to a particular level called saturated level. After this level the output voltage remains unaltered even in increase in light intensity. Whenever the dust is formed or the temperature of the panel rises, the saturated level decreases. The output of the solar panel is too high to damage the microprocessor and components; hence we need to step down the voltage of the solar panel. So, we have used voltage divider made of resistors.

Thus by fixing the values of $\mathrm{R} 1$ and $\mathrm{R} 2$ as $15 \mathrm{k} \Omega$ and $5 \mathrm{k} \Omega$ respectively we get the output voltage in terms of $5 \mathrm{~V}$ by below.

$$
\begin{gathered}
V_{\text {out }}=V_{\text {in }}\left(\frac{R_{2}}{R_{1}+R_{2}}\right) \\
V_{\text {out }}=20\left(\frac{5000}{15000+7000}\right) \\
V_{\text {out }}=5 \mathrm{~V}
\end{gathered}
$$

Thus the output voltage will be in the range of 0 to $5 \mathrm{~V}$.

\subsection{External Monitoring Unit}

The peak saturated value cannot be fixed; it changes with the external light intensity. Thus EMU is used for analyzing the external light intensity to keep that as reference voltage which 
is to be compared with the solar panel output voltage. Photoresistors are kept in a way such that it represents the light intensity falling on solar panel and external light intensity.

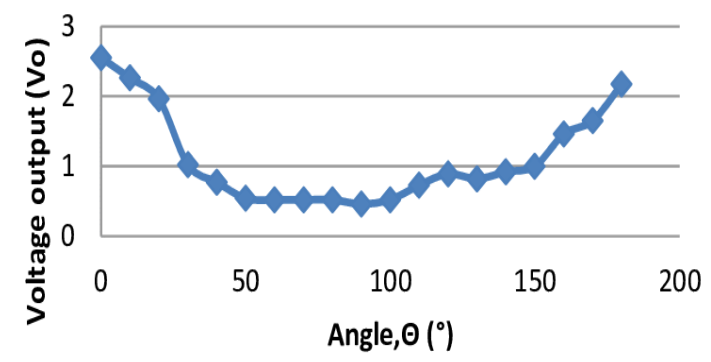

Fig 1.6 Output Voltage of PR vs Angle of incident light

Table 1 Output Voltage of PR with respect to light intensity

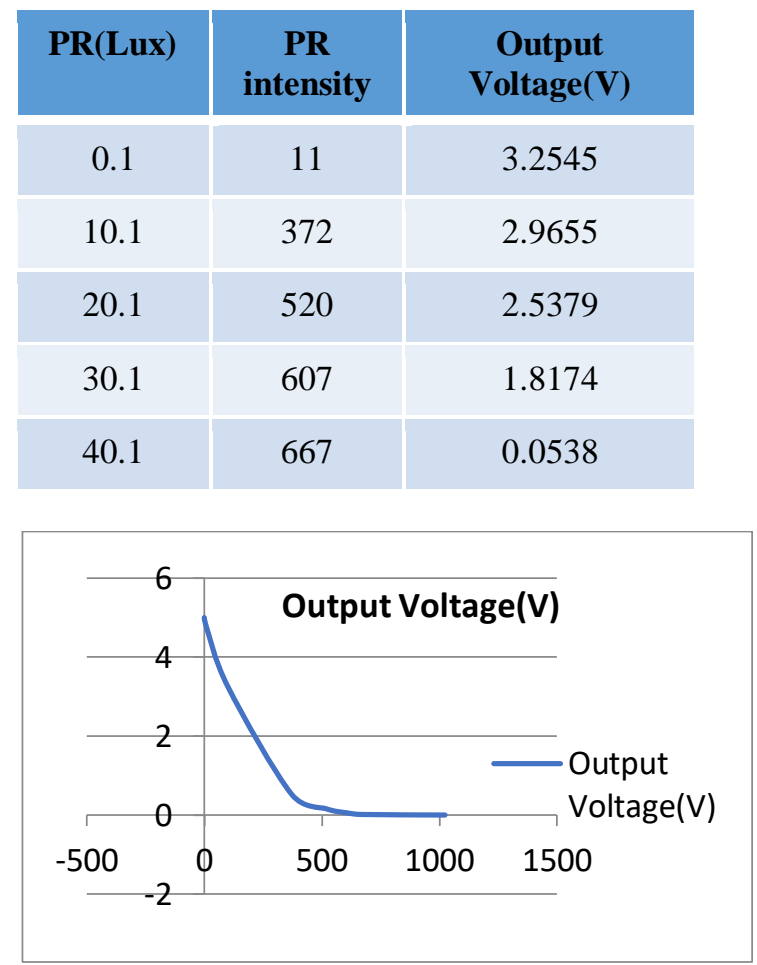

Fig 1.7 Curve obtained for above Table 1

The voltage output of the PR is varied with the angle of sunlight and also with the light intensity. Fig 1.6shows that the output voltage of PR is varied with the angle of sunlight incident on the surface. The maximum voltage is obtained in the angle $0^{\circ}$. The above Table 1.1 shows the change in output voltage of PR with the change of light intensity which shows that lower the light intensity higher the output voltage. The equation obtained from the curve plotted in Fig 1.7 is given as, 
$\mathrm{V}_{\mathrm{PR}}$ - Photoresistor Voltage

$$
V_{P R}=\frac{C}{L+1}+M
$$

C - Proportionality Constant

L - Light intensity

M - Magnitude Constant

At dark environment the value of $\mathrm{L}=0$ and $\mathrm{V}_{\mathrm{PR}}$ is at maximum value whereas at bright light the value $\mathrm{L}$ is maximum and $\mathrm{V}_{\mathrm{PR}}=0$. Thus we get,

In our system $\mathrm{L}_{\max }=1024$ and $\mathrm{V}_{\mathrm{PR}, \max }=5 \mathrm{~V}$.

$$
\begin{gathered}
M=V_{P R, \max } / L_{\text {max }} \\
C=\left(1-\frac{1}{L_{\text {max }}}\right) V_{P R, \max }
\end{gathered}
$$

\subsection{Processing Unit}

The outputs of SPU and EMU are compared in this processing unit based on a condition and a signal is sent to operate the cleaning unit. The processing unit consists of a microcontroller for that purpose Arduino is used.The complex condition can be formulated from the graphs Fig 1.2, Fig 1.3, Fig 1.6 and the Table 1.1. On basis of analysis of these graphs we get the three dimensional curve which is shown below.

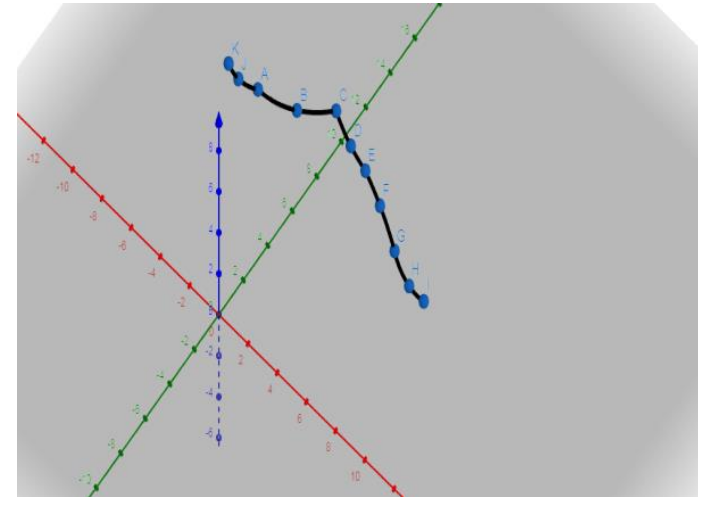

Fig 1.8 Top view of resultant curve

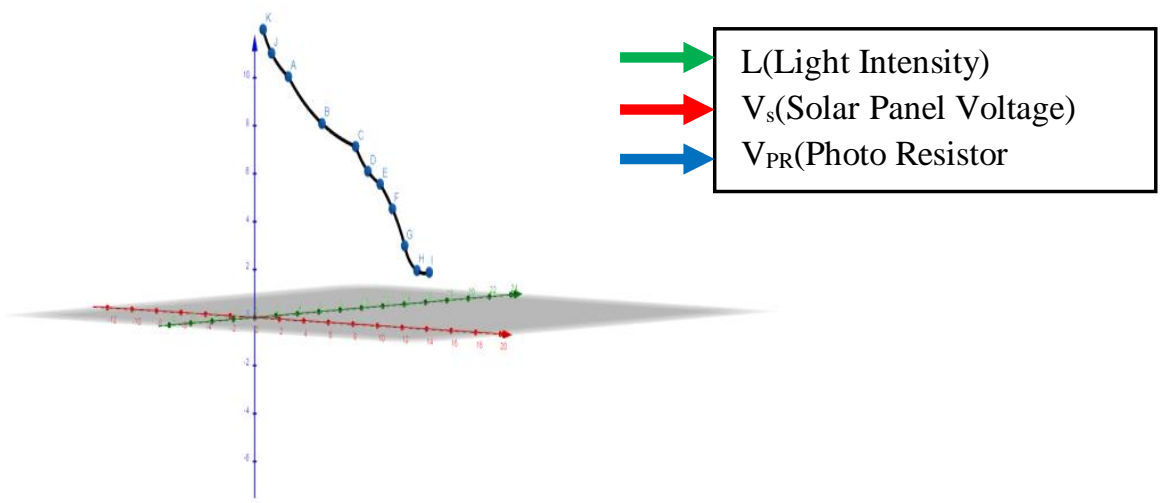

Fig 1.9 Side view of resultant curve 
The point $\mathrm{C}$ in the curve (can be seen clearly in Fig 1.8) is referred as setpoint from which the solar panel attains saturation as shown in section 1.1. The equation is obtained by the equations in the Solar Panel Unit and External Monitoring Unit which is given below.

C - Proportionality Constant

$$
V_{P R}=\left(\frac{C}{\left(\sqrt{\left(V_{S}^{2}+a L^{2}\right)}\right)+1}\right)-M
$$

a - Light intensity multiplier $\left(V^{2} /\right.$ lumens $\left.^{2}\right)$

$\mathrm{M}$ - Magnitude Constant

The values of $\mathrm{C}$ and $\mathrm{M}$ are found using dark environment and bright light. At dark environment the values of $L, V_{S}$ are 0 and the value of $V_{P R}$ is at maximum value $V_{P R, m a x}$, whereas at bright environment the values of $L$ be at maximum value $L_{\max }$ and $V_{S}$ be at saturated voltage $\mathrm{V}_{\text {sat }}$ but the value of $\mathrm{V}_{\mathrm{PR}}$ is at 0 .

$$
\begin{gathered}
M=\frac{V_{P R, \text { max }}}{\sqrt{\left(V_{\text {sat }}^{2}-a L_{\text {max }}^{2}\right)}} \\
C=\left(1+\left(\frac{1}{\sqrt{\left(V_{\text {sat }}^{2}-a L_{\text {max }}^{2}\right)}}\right)\right) V_{P R, \text { max }}
\end{gathered}
$$

These data are fed to Arduino by entering the above expressions in Arduino IDE.

\subsection{Cleaning Unit}

The cleaning unit consists of a DC motor, $12 \mathrm{~V}$ battery,helical worm gear unit, Wiper, Water pump and Two channel relay for controlling both. The shaft of DC motor is coupled with helical gear unit. This unit consists of a worm shaft and a gear.

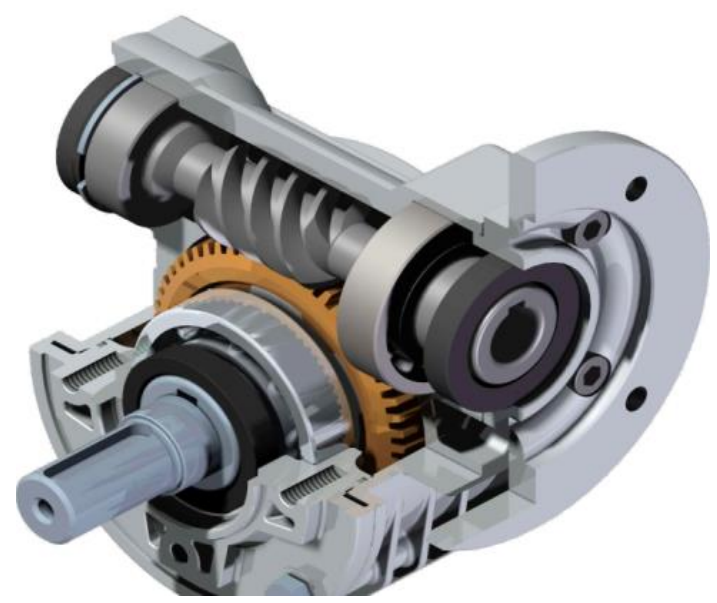

Fig 1.10 Gear system used in our model

The rotational to linear motion is done by a crank shaft which is connected to a slider. The slider is flat plate consists of two bushes which passes two rods by giving a sliding mechanism. The torque acquired by the slider is very huge thus helical worm gear unit is used. 


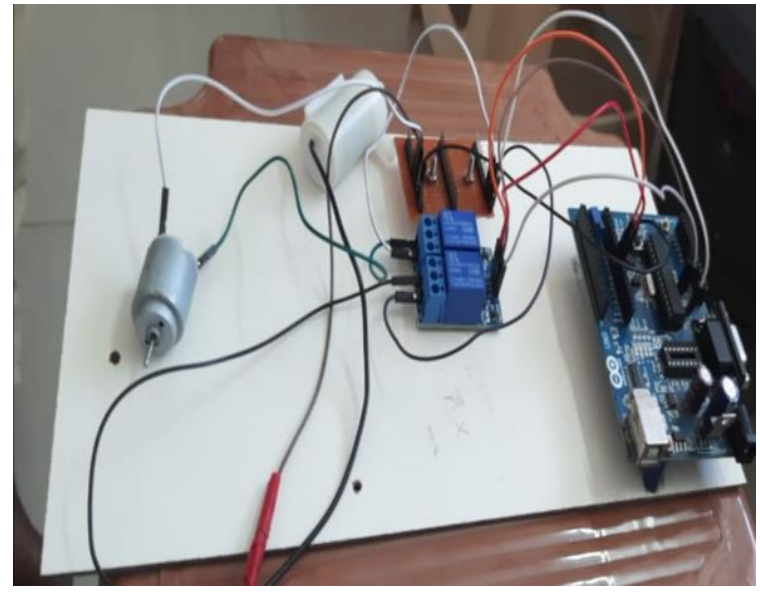

Fig 1.11Circuit to control Motor actuation

This unit activates when the condition signal from the Processing Unit becomes false as shown in Fig 1.1. The water sprayer is not only used for cleaning purpose but also used for controlling the temperature.

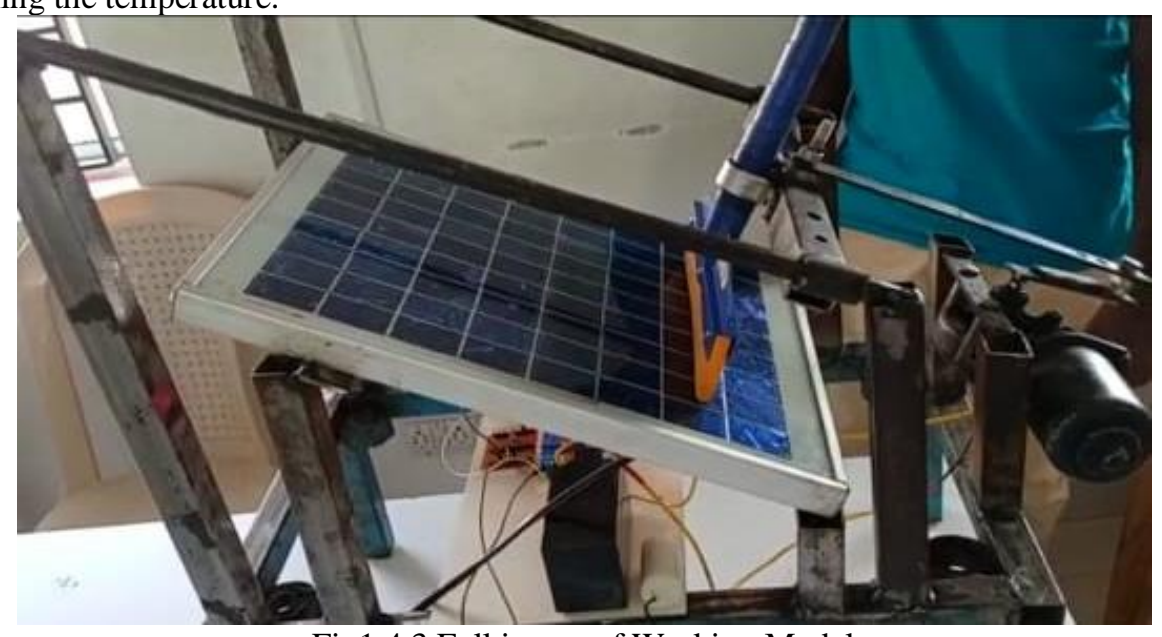

Fig1.4.3 Full image of Working Model 


\section{Testing And Results}

\begin{tabular}{|l|l|l|l|l|l|}
\hline $\begin{array}{l}\text { Light } \\
\text { intensity } \\
(\mathrm{L})\end{array}$ & $\begin{array}{l}\text { Solar } \\
\text { Panel } \\
\text { Voltage } \\
\left(V_{S}\right)\end{array}$ & $\begin{array}{l}\text { Photo } \\
\text { resistor } \\
\text { Voltage } \\
\left(V_{\text {PR }}\right.\end{array}$ & $\begin{array}{l}\text { Dust } \\
\text { Accumulated }\end{array}$ & $\begin{array}{l}\text { Expected } \\
\text { Action } \\
\text { (Clean/ } \\
\text { Skip) }\end{array}$ & $\begin{array}{l}\text { Results } \\
\text { (Clean/ } \\
\text { Skip) }\end{array}$ \\
\hline 1024 & 7.3321 & 0 & No & Skip & Skip \\
\hline 1024 & 6.2132 & 0 & Yes & Clean & Clean \\
\hline 667 & 3.4376 & 0.0538 & No & Skip & Skip \\
\hline 667 & 3.4376 & 0.0538 & Yes & Clean & Clean \\
\hline
\end{tabular}

Table 2.1Parmeter Values noted and the output prescision

The output of the solar panel on regular cleaning with our model has an increased efficiency to $27.2 \%$ than that of which is not cleaned properly.

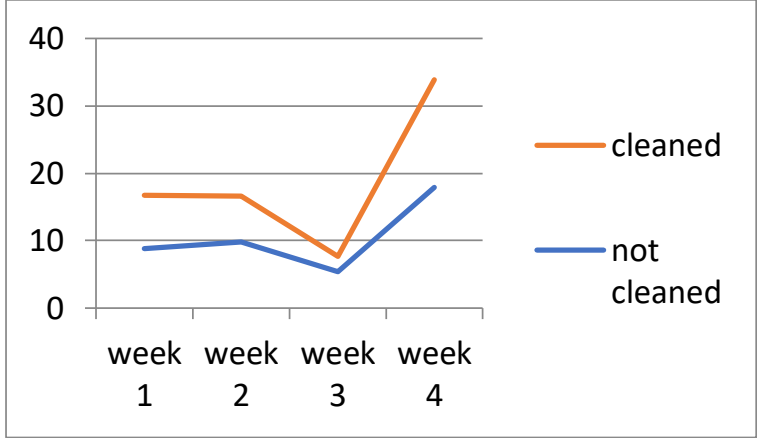

Fig 2.1 Weekly observance of the output difference

\section{Conclusion}

The designing of solar panel cleaning system was first taken into consideration. The base for the solar panel is made by mild steel for bearing the weight of solar panel and the other weights. The choice of motor to actuate the crank shaft was a little confusing thing. The idea of comparing voltages was easy at first but it was gone tedious on proceeding to next steps because the voltage curves are not linear and the resulting curve to be fed in microcontroller was been a great task. Then the motor and wiper is checked for a long time to fit the solar panel surface.

\section{References}

[1] Sayyah, A,. Horenstein M., and Mazumder M. (2016) 'Mitigation of Soiling Losses in Concentrating Solar Collectors.' IEEE 39th Photovoltaic Specialists Conference(PVSC)404408. Print.

[2] Burton, D., and Bruce H. King. (2016) 'Spectral Sensitivity of Simulated Photovoltaic Module Soiling for a Variety of Synthesized Soil Types.' IEEE Journal of Photovoltaics IEEE J. Photovoltaics 4.3 890-98. Print. 
[3] Creyts, J., and Guccione, L. (n.d.), (2016), 'The Economics of Grid Defection (Rep.).' from Rocky Mountain Institute website:

[4] http://www.rmi.org/electricity_grid_defection\#economics_of_grid_defection

[5] Allen McFarland (2016) California First State To Generate More Than 5\% Of Electricity From Utility-Scale Solar -Today In Energy - U.S. Energy Information Administration (EIA)'.

[6] http://www.eia.gov/todayinenergy/detail.cfm?id=20492

[7] Tavares, S. (2016) 'Dirty Detail: Solar Panels Need Water' LasVegasSun.com. N. http://lasvegassun.com/news/2009/sep/18/dirty-detail-solar-panels-need-water/

[8] Boyle L., Flinchpaugh H., and Hannigan M. (2013) 'Impact of Natural Soiling on the Transmission of PV Cover Plates.' IEEE 39th Photovoltaic Specialists Conference (PVSC)

[9] Cabanillas R.E. and Munguia H. (2011), "Dust accumulation effect on efficiency of Si photovoltaic modules" Journal of Renewable and sustainable energy 3, 043114 Print

[10] Park Y B, Im H, Im M, et al.( 2011) 'Self-cleaning effect of highly water-repellent microshell structures for solar cell applications.' Journal of Materials Chemistry,; 21:633-636.

[11] Zhu Jia, Hsu Ching Mei, Yu Zongfu, et al. (2010) 'Nanodome solar cells with efficient light management and self-cleaning'. Nano Letter, 10:1979-1984.

[12] Liu G Q, Marshall J S,(2010) 'Effect of particle adhesion and interactions on motion by traveling waves on an electric curtain.' Journal of Electrostatics, 68:179-189.

[13] Sharma R, Wyatt C A, Zhang Jing, et al. (2009) 'Experimental evaluation and analysis of electrodynamic screen as dust mitigation technology for future Mars missions.' IEEE Transactions on Industry Applications; 45( 2):591-596.

[14] Williams R B, Tanimoto R, Simonyan A, et al., (2007) 'Vibration characterization of selfcleaning solar panels with piezoceramic actuation.' Collection of Technical Papers - 48th AIAA/ASME/ASCE/AHS/ASC Structures, Structural Dynamics, and Materials Conference , pp. 512-520.

[15] Kimber, A., L. Mitchell, S. Nogradi, and H. Wenger. (2006) 'The Effect of Soiling on Large Grid-Connected Photovoltaic Systems in California and the Southwest Region of the United States.' IEEE 4th World Conference on Photovoltaic Energy Conference

[16] Tomoaki Yano, Tomohiro Suwa, Masato Muraxami And TakujiYamamotq (1997), 'Development of a Semi Self-contained Wall Climbing Robot with Scanning Type Suction Cups' Intelligent Robots and Systems, IROS 97., Proceedings of the 1997 IEEE/RSJ International Conference

[17] El-Shobokshy MS, Hussein FM. (1993) 'Degradation of photovoltaic cell performance due to dust deposition on to its surface.' J Renew Energy (6/7):585e90.

[18] El-Shobokshy MS, Mujahid A, Zakzouk AKM.(1985) 'Effects of on the performance of concentrator photovoltaic cells', IEE Proc;132(1). Pt. I.

[19] Masuda S, Aoyoma M. (1971), 'Characteristics of electric dust collector based on electric curtain.' Proceedings of the General Conference of the Institute of Electronic Engineers. Japan, No. 821 Proc. of Albany Conference on Electrostatics .

[20] http://www.mbl-energy.com/santa-clara-university.html

[21] http://www.ecoppia.com/ecoppia-e4

[22] http://www.solarpanelcleaningsystems.com/about-us.html 